Volume, 14, n. 1, ano, 2018.

\title{
O ENSINO DE MATEMÁTICA POR MEIO DAS TECNOLOGIAS DIGITAIS
}

\author{
Stelamara Souza Pereira ${ }^{1}$ \\ Flomar Ambrosina Oliveira Chagas ${ }^{2}$
}

RESUMO Este trabalho apresenta o produto educacional de uma pesquisa de dissertação do Programa de Mestrado Profissional do Instituto Federal de Educação, Ciência e Tecnologia de Goiás, Câmpus Jataí. O produto foi um curso intitulado Redação Matemática como estratégia de ensino na prática pedagógica com carga horária de 120 horas, realizado durante quatro meses, para professores que lecionavam Matemática no Ensino Fundamental, da educação infantil ao $9^{\circ}$ ano, do município de Doverlândia-GO. O objetivo foi desenvolver um trabalho com professores sobre novas possibilidades de comunicação, destacando a Redação Matemática, por meio de Histórias em Quadrinhos, Carta e Diário, como estratégia de ensino na prática pedagógica, permitindo que os alunos explorassem os conteúdos matemáticos, que possibilitassem a eles se expressarem, se autoavaliarem e que se compreendessem os significados dos conceitos estudados nas aulas de Matemática. Por fim, importante o uso da Redação Matemática na prática pedagógica, sua aplicabilidade e sua potencialidade, das tecnologias digitais como uma ferramenta para o aprendizado, visto que os participantes se dedicaram às atividades propostas, mesmo diante dos desafios da carga horária excessiva, do deslocamento do campo para a cidade e das precárias condições dos laboratórios de informática.

Palavras-chave: tecnologias digitais, ensino-aprendizagem, leitura e escrita matemática.

\section{THE TEACHING OF MATHEMATICS BY DIGITAL TECHNOLOGIES}

ABSTRACT This work presents the educational product of a dissertation research of the Professional Master's Program of the Federal Institute of Education, Science and Technology of Goiás, Câmpus Jataí. The product was a course entitled Mathematical Writing as a strategy of teaching in pedagogical practice with a 120-hour workload, carried out during four months, for teachers who taught Mathematics in elementary education, in the 9th grade, in the

\footnotetext{
${ }^{1}$ Mestra, professora no Centro Universitário de Mineiros-GO/UNIFIMES. E-mail: stelamara@ gmail.com

${ }^{2}$ Doutora em Educação, professora no programa de pós-graduação do Instituto Federal de Goiás/IFG/Câmpus Jataí. E-mail: flomarchagas@gmail.com
} 
Volume, 14, n. 1, ano, 2018.

municipality of Doverlândia-GO. The objective was to develop a work with teachers on new possibilities of communication, highlighting the Mathematical Writing, through Stories in comics, letter and diary, as teaching strategy in pedagogical practice, allowing the students to explore the mathematical contents, to enable them to express themselves, self-evaluate and to understand the meanings of the concepts studied in Mathematics classes. Finally, it is important to use Mathematical Writing in pedagogical practice, its applicability and its potential, of digital technologies as a tool for learning, since the participants have dedicated themselves to the proposed activities, even in the face of the challenges of excessive workload, from the countryside to the city and from the precarious conditions of the computer laboratories.

keywords: Digital technologies, teaching-learning, reading and mathematical writing.

\section{Introdução}

Este trabalho apresenta o produto educacional de uma pesquisa de dissertação do Programa de Mestrado Profissional do Instituto Federal de Educação, Ciência e Tecnologia de Goiás, Câmpus Jataí, concluído no segundo semestre de 2015. Teve como objetivo desenvolver um curso com professores do ensino fundamental sobre novas possibilidades de comunicação, destacando a Redação Matemática/RedMat, por meio de Histórias em Quadrinhos, Carta e Diário, como estratégia de ensino na prática pedagógica, permitindo que os alunos explorassem os conteúdos matemáticos, que possibilitassem a eles se expressarem, se autoavaliarem e que se compreendessem os significados dos conceitos estudados nas aulas de Matemática, e ainda que o curso RedMat se tornasse um produto vinculado ao Mestrado Profissional em Educação para Ciências e Matemática do Instituto Federal de Goiás, Câmpus Jataí.

Os objetivos específicos foram: conhecer as ferramentas do ambiente de aprendizagem Moodle; explorar outras ferramentas de edição de textos como o software Hagáquê; refletir sobre o uso das tecnologias na educação; compreender a importância da leitura e da escrita na Matemática; motivar os professores a debater e a inovar as sequências didáticas, voltadas para o ensino-aprendizagem com HQ; compreender a importância do pensamento matemático na produção da carta e do diário; identificar as potencialidades e as limitações das HQ, das Cartas e dos Diários no ensino de Matemática, pois "escrever textos sobre conclusões, comunicar resultados, usando ao mesmo tempo elementos da língua materna e alguns símbolos matemáticos, são atividades importantes para que a linguagem Matemática não funcione como um código indecifrável para os alunos” (BRASIL, 1998, p. 46). 
Volume, 14, n. 1, ano, 2018.

O curso teve a perspectiva de levar o docente a novas concepções de ensinar Matemática, de aliar teoria e prática na construção do conhecimento e de integrar as Tecnologias digitais como ferramentas de apoio pedagógico, proporcionando um trabalho de interação com os sujeitos envolvidos.

A escolha pela temática ocorreu pela dificuldade de muitos alunos do Ensino Fundamental apresentar no processo de ensino-aprendizagem da Matemática em relação à compreensão dos conteúdos por, muitas vezes, serem apresentados de maneira formalizada, descontextualizada, justificando assim, o porquê de se trabalhar com a escrita na Matemática na formação de professores.

Para D’Ambrósio (2012), a educação formal é, na maioria das vezes, baseada na mera transmissão de explicações e de teorias ou na prática de exercícios repetitivos. Para o autor, "o grande desafio que se encontra na educação é justamente sermos capazes de interpretar as capacidades e a própria ação cognitiva não da forma linear, estável e contínua que caracteriza as práticas educacionais mais correntes" (D’AMBROSIO, 2012, p. 109).

Desse modo, é necessário que as instituições escolares deem condições de trabalho ao professor para que ele seja capaz de inserir novos instrumentos pedagógicos que permitam aos seus alunos se envolverem com a Matemática, dando significado aos conteúdos estudados. Como afirma Pais (2013, p. 75), "é preciso valorizar estratégias de ensino que envolvam diferentes linguagens e não priorizar a dimensão abstrata dos conceitos, esperando que a aprendizagem da linguagem se efetue num segundo momento". Esse fato chama a atenção para desenvolver atividades que ultrapassem os limites do conteúdo aprendido em sala de aula. Pensando assim, propôs o desenvolvendo de um trabalho com professores da rede municipal de ensino de Doverlândia - GO, na perspectiva de aliar a Redação Matemática com a tecnologia para discutir o conteúdo matemático, de tal forma que pudesse contribuir com a aprendizagem dos alunos.

Os limites físicos da sala de aula já estão superados pelo advento dos mecanismos tecnológicos, é necessário que o aluno esteja apto a construir seu conhecimento fora da sala de aula, como menciona Valente (1999, p. 36), o aluno "deve sair da passividade de quem só recebe para se tornar ativo caçador da informação, de problemas para resolver e de assuntos para pesquisar". Assim, surge o desafio de o professor ultrapassar os limites da sala de aula para desenvolver atividades alternativas de aprendizagem. Para tanto, "os professores 
Volume, 14, n. 1, ano, 2018.

precisam atualizar-se, permanentemente, acompanhando o desenvolvimento da ciência e da tecnologia (os mestres são os intermediários entre as pesquisas, descobertas e inovações, e as novas gerações)" afirma Lima (1999), citado por Nunes, et. al. (2009, p.12).

Desta forma, a produção de redações Matemáticas por meio da informática, permite ao docente criar um espaço de comunicação estabelecendo uma relação prazerosa com os alunos e uma diferente percepção da Matemática, visto que é um espaço dominado e frequentado por eles.

\section{Abordagem metodológica}

Esta é uma pesquisa de abordagem qualitativa, configura como pesquisa-ação. De acordo com Triviños (2012), a pesquisa qualitativa tem ambiente natural como fonte direta dos dados e o pesquisador como instrumento-chave; é descritiva, preocupa com o processo e não simplesmente com os resultados e o produto, tende analisar os dados indutivamente e o significado nessa pesquisa é a preocupação essencial.

A pesquisa-ação configura-se como investigação e como transformação da prática. E no ambiente escolar, ela é um meio

a) de sanar os problemas diagnosticados em situações específicas, ou melhorar de alguma maneira um conjunto de circunstâncias; b) de treinamento em serviço, portanto, proporcionando ao professor novas habilidades, métodos para aprimorar sua capacidade analítica e o fortalecimento da autoconsciência; c) de introduzir abordagens adicionais e inovadoras no processo ensino-aprendizagem e aprender continuamente em um sistema que normalmente inibe a mudança e a inovação; d) de melhorar a comunicação entre o professor praticante e o pesquisador acadêmico na tentativa de remediar a deficiência da pesquisa tradicional de dar prescrições claras; e e) de proporcionar uma alternativa à solução de problemas na sala de aula. (MOREIRA; CALEFFE, 2008, p. 92)

Assim sendo, realizou esta pesquisa com professores do ensino fundamental por meio de um curso de formação continuada, em que a pesquisadora assume papel de investigadora da própria prática para compreender os sentidos que os docentes atribuem à inserção de tecnologias no ensino, à leitura e à escrita na Matemática e ainda socializar novos conhecimentos com um grupo de professores.

\section{Curso de formação continuada de professores}


Volume, 14, n. 1, ano, 2018.

O curso intitulado Redação Matemática como estratégia de ensino na prática pedagógica/RedMat teve duração de quatro meses, de agosto a novembro, num total de 120 horas, realizado em 25 encontros, sendo treze presenciais e doze à distância, ministrados no Laboratório de Informática do Telecentro Municipal para doze professores que lecionavam Matemática no Ensino Fundamental, da educação infantil ao $9^{\circ}$ ano, do município de Doverlândia-GO.

Durante os encontros, foi realizada uma abordagem teórica e prática em relação à RedMat, quando se discorreu sobre as diversas possibilidades de envolver os alunos na escrita na Matemática, mostrando-lhes a importância de compreender os signos e significados do que se estuda.

No primeiro encontro foi feita a apresentação do curso, informações sobre as oficinas sobre as tecnologias digitais, foi aplicado questionário, e solicitado a assinatura dos termos de consentimento livre. Na oportunidade, foi esclarecido também quanto ao formato do curso que foi realizado em encontros presenciais uma vez por semana, com duração de três horas. E as demais horas eram dedicadas, durante a semana, a discussões sobre os assuntos abordados no encontro presencial foram moderados e discutidos por meio virtual, utilizando a plataforma Moodle (Modular Object-Oriented Dynamic Learning Environment) um ambiente virtual de aprendizagem. De acordo com seu criador, Martin Dougiamas, trabalha numa perspectiva dinâmica da aprendizagem em que a pedagogia socioconstrucionista e as ações colaborativas ocupam lugar de destaque. Nesse contexto, ocorre a interação dos participantes, permitindo a construção/reconstrução do conhecimento (SILVA, 2011).

O questionário inicial foi aplicado para verificar aspectos sócio-econômico-culturais e obter dados sobre aspectos pedagógicos. Conforme Moreira e Caleffe (2008, p. 95), “o questionário tem sido uma das maneiras mais populares para coletar dados. [...] as respostas podem ser quantificadas por meio de técnicas estatísticas sofisticadas e os resultados apresentados com toda a confiança que os números trazem".

A opção pelo curso semipresencial foi para oportunizarem aos docentes a participarem do curso, visto que eles tinham cargas horárias elevadas em suas respectivas escolas e alguns deles trabalhavam em escolas do campo. De acordo com Borges (2005), a modalidade de educação semipresencial é destacada como sendo também uma modalidade híbrida de educação, na qual essa hibridação significa a (re) elaboração da modalidade de educação 
Volume, 14, n. 1, ano, 2018.

presencial com novos métodos e novas concepções educacionais, permitindo aos professores interagir com colegas e com pesquisadores sempre antes do encontro presencial.

O material do curso, o produto, foi sendo construído à medida que os encontros aconteciam. Assim, foi possível compreender a realidade dos participantes para elaborar material para os próximos encontros sobre as três modalidades, sendo: Histórias em Quadrinhos (HQ), Carta e Diário. Essas atividades foram abordadas utilizando-se as Tecnologias Digitais (TD). Ministrou-se a modalidade HQ por meio do software HagáQuê, apresentando as ferramentas que o software oferece e, em seguida, a modalidade Carta e Diário, utilizando-se do computador para redigir os textos.

O Hagáquê é um software educativo, que permite explorar a linguagem escrita, possuindo um banco de imagens, com cenários, personagens e outros recursos que possibilitam o aluno a usar sua imaginação em diversas áreas do conhecimento; foi desenvolvido de modo a facilitar a criação das Histórias em Quadrinhos, auxiliando o professor no processo de ensino-aprendizagem de Língua Portuguesa, de Ciências, de Matemática e de outras disciplinas. Esse software permite trabalhar com figuras, textos, sons e também possui ferramentas para desenhar formas geométricas simples (retas, retângulos e elipses).

Como atividades, os professores foram orientados a desenvolver uma sequência didática em sua turma, discuti-la nos encontros presenciais para, em seguida, aplicá-la com seus alunos, envolvendo as ferramentas tecnológicas como apoio pedagógico, no caso da HQ, o software HagáQuê. E após a aplicação da sequência, os professores retornariam aos encontros com os resultados obtidos para discussão e para troca de experiências.

Os encontros à distância foram realizados pelo ambiente virtual de aprendizagem Moodle e, por meio dele, a pesquisadora acompanhou todo o processo de formação e moderou as atividades dos professores participantes, ocorrendo interação dos participantes, tanto nos fóruns, quanto na realização das tarefas na plataforma, proporcionando um novo espaço de comunicação, de debate, de partilha de ideias, de opiniões sobre a temática proposta.

Os docentes tiveram a oportunidade de produzir suas próprias sequências didáticas utilizando Histórias em Quadrinhos (HQ), Cartas e Diários, verificando a possibilidade de esses recursos serem usados para ministrarem os conteúdos que estavam sendo desenvolvidos. Dessa forma, os professores foram motivados a discutirem problemas matemáticos tratados 
Volume, 14, n. 1, ano, 2018.

em sala de aula e a interligarem seus conhecimentos matemáticos com o cotidiano nas produções. Sendo assim, a pesquisadora, além de acompanhar o desenvolvimento dos participantes em relação aos sentidos que, eles deram a esses instrumentos pedagógicos, ainda teve a oportunidade de avaliar as potencialidades que a leitura e a escrita puderam oferecer aos docentes.

Todos os encontros foram filmados e gravados a áudio. Para finalizar a pesquisa, foi realizada uma entrevista com os participantes do curso para analisar as principais dificuldades apresentadas, verificando se a RedMat possibilitou a compreensão de conceitos matemáticos, e se também compreendeu que a Matemática ia além de números e de fórmulas, mostrandolhe ser fundamental a escrita na Matemática. Doze participantes tiveram $75 \%$ de frequência e média acima de sete nas atividades presenciais e à distância e receberam certificados. A nota final obtida no curso foi composta por sessenta por cento de atividades presenciais e quarenta por cento de atividades à distância.

Os materiais de coleta de dados utilizados na análise dessa pesquisa foram: questionários, entrevista semiestruturada, registros nos fóruns, diários de campo (observações registradas pela pesquisadora), atividades realizadas pelos docentes, filmagens e as gravações de áudio. A análise de conteúdo se deu se acordo com Bardin (2011, p. 125). No quadro 1, constam as categorias que direcionaram a análise dos resultados.

\section{Quadro 1 - Categorias de análise da pesquisa}

\begin{tabular}{|c|c|}
\hline \multirow{3}{*}{$\begin{array}{c}\text { Sentidos atribuídos pelos } \\
\text { docentes às sequências } \\
\text { didáticas }\end{array}$} & Complementação \\
\cline { 2 - 2 } & Construção de conceitos \\
\cline { 2 - 2 } & Motivação \\
\cline { 2 - 2 }
\end{tabular}

Fonte: Elaboração das próprias pesquisadoras

Com base nessas categorias de análise, buscou-se compreender as concepções que os professores apresentaram nas sequências didáticas sobre Histórias em Quadrinhos, Cartas e Diários. Para isso, investigou: quando o sentido de ilustração passa a ser significativo no contexto da Educação Infantil e do Ensino Fundamental? Os docentes aplicaram suas sequências didáticas no sentido de complementação de um conteúdo já abordado ou complementou esse conteúdo utilizando-se da interdisciplinaridade? Houve construção de 
Volume, 14, n. 1, ano, 2018.

conceitos ao elaborar a sequência didática provocando o aluno para se expandir na escrita na Matemática? O docente trabalhou a Matemática com atividades motivacionais? Essas questões foram essenciais para a compreensão dos sentidos que os docentes atribuíram ao elaborar as sequências didáticas.

Estas questões nortearam a análise dessa pesquisa e, por meio das sequências didáticas, as características de cada prática docente foram identificadas. A investigação dos sentidos que os professores atribuíram aos recursos educacionais HQ, Carta e Diário, possibilitou compreender aqueles docentes que demonstraram uma visão de construção dos conceitos matemáticos.

Compreender aqueles que demonstraram os sentidos de motivar o aluno, também de desenvolver as atividades por meio de ilustrações, tanto manuais quanto digitais e ainda os que apresentaram o sentido de complementação, utilizando atividades interdisciplinares e inserindo conteúdos trabalhados em sala de aula. Desse modo, os resultados mostraram que nas sequências didáticas utilizando HQ destacou-se o uso das ilustrações para expressar conhecimentos matemáticos; e nas sequências didáticas, com os recursos educacionais Carta e Diário, notou-se que além do docente resgatar a cultura da carta, dos registros nos diários, foilhes possível discutir a importância desses instrumentos como prática de auto-avaliação e de expressão dos sentimentos na manifestação dos conhecimentos. É importante destacar, que esses recursos educacionais foram instrumentos de reflexão para pensar em futuras pesquisas, quando se percebe que há muitas possibilidades de inseri-los na prática pedagógica.

Analisando o processo de desenvolvimento da escrita na Matemática com as Tecnologias Digitais, verificou-se que estas constituem ferramentas de múltiplas possibilidades, que contribuíram para auxiliar os desenhos na construção no software HagáQuê, a diversificar as Cartas e os Diários, para a aprendizagem Matemática. Isso se evidenciou quando os docentes mostraram que com TD os alunos ficaram motivados a desenvolver atividades.

Os conteúdos trabalhados nas diferentes séries (da educação infantil ao $9^{\circ}$ ano), durante o curso foram: sistema de medida, perímetro e área de figuras plana, termo algébrico: (monômio e polinômios); Operações com termos algébricos; Expressões algébricas; Equações; Geometria e proporcionalidade; as quatro operações básicas (adição, subtração, multiplicação e divisão); Situações-problemas; Leitura, interpretação e escrita; Produção de 
Volume, 14, n. 1, ano, 2018.

história em quadrinhos, de cartas e de diários; Jogos (na trilha da Matemática); Representação dos números naturais através do material dourado. Gráficos e tabelas; Sistema de medida (perímetro), Polígonos, triângulos e quadriláteros; Tabelas e gráficos; Hidrografia; Números negativos e positivos; Ângulos; Ângulos Complementares e Suplementares e Ângulos Opostos pelo Vértice.

Foram apresentadas sugestões de planos de unidade semanais (presenciais e à distância), bem como possibilidades de ferramentas tecnológicas para trabalhar a leitura e a escrita, e os tutoriais de apoio para os seus trabalhos para compreender os demais aspectos, como o envolvimento dos professores, as discussões realizadas, as principais dificuldades apresentadas e a elaboração das sequências didáticas pelos docentes.

\section{Considerações finais}

Este produto educacional é resultado de uma pesquisa de mestrado desenvolvido com professores da rede estadual e municipal de ensino a fim de contribuir com a prática pedagógica do professor de Matemática. Mais detalhe sobre o curso e aplicação dele poderá acessar o site no link: http://redmatematica.webnode.com//

$\mathrm{O}$ referido curso mostrou proveitoso aos docentes, pois eles se sentiram motivados a desenvolver atividades de Matemática utilizando os recursos de aprendizagem, desenvolvendo com seus alunos a construção de histórias em quadrinhos, a elaboração de cartas e o registro em diários, enfatizando os conhecimentos matemáticos por meio da leitura e da escrita.

Ao longo do desenvolvimento do curso, os docentes demonstraram interesse em retomar as atividades com outras turmas; compreenderam a necessidade de inserir a leitura e a escrita nas aulas de Matemática e perceberam que as dificuldades com as tecnologias digitais existem, e que o curso foi uma forma de superá-las. Assim, eles sugeriram a realização de novos cursos de formação de professores, pois eles tinham interesse em participar e se sentiram até incentivados com a ideia de cursar uma pós-graduação em nível de mestrado.

Evidenciou-se a importância do uso da Redação Matemática na prática pedagógica, sua aplicabilidade e sua potencialidade, das tecnologias digitais como uma ferramenta para o aprendizado, visto que os participantes se dedicaram às atividades propostas, mesmo pelos 
Volume, 14, n. 1, ano, 2018.

desafios da carga horária excessiva, deslocamento do campo para a cidade e das precárias condições dos laboratórios de informática.

\section{Referências}

BARBOSA, K. C. B. A.; NACARATO, A. M.; PENHA, Paulo César da. A escrita nas aulas de Matemática revelando crenças e produção de significados pelos alunos. Série-estudos: Periódico do Mestrado em Educação da UCDB, Campo Grande-MS, v. 26, n. 1, p.81-84, jul. 2008.

BARDIN, L. Análise de conteúdo. Tradução de: Luís Antero Reto, Augusto Pinheiro. 70. ed. São Paulo: Almedina Brasil, 2011.

BARRETO, R. G. As políticas de formação de professores. In: BARRETO, Raquel Goulart. Formação de professores, tecnologias e linguagens. São Paulo: Loyola, 2002. Cap. 3. p. $110-118$.

BORGES, M. K. Educação Semipresencial: desmistificando a Educação a Distância. ABED, Maio/2005. Disponível em: http://www.abed.org.br/congresso2005/por/pdf/218tcf3.pdf. Acesso em: 21. fev. 2015.

BRASIL. Ministério da Educação e do Desporto. Secretaria de Educação Fundamental. Parâmetros Curriculares Nacionais: Matemática - Terceiro e Quarto Ciclo do Ensino Fundamental. Secretaria de Educação Fundamental. Brasília: MEC / SEF, 1998.

D’AMBRÓSIO, U. Educação Matemática: da teoria à prática. 23. ed. Campinas, SP: Papirus, 2012.

MOREIRA, H.; CALEFFE, L. G. Metodologia da pesquisa para o professor pesquisador. 2. ed. Rio de Janeiro: Lamparina, 2008.

NUNES, T. et al. Educação Matemática: números e operações numéricas. 2. ed. São Paulo: Cortez, 2009.

PAIS, L. C. Ensinar e aprender Matemática. 2. ed. Belo Horizonte: Autêntica, 2013.

SILVA, R. S. da. Moodle para autores e tutores. 2. Ed. São Paulo: Novatec editora, 2011.

TRIVIÑOS, A. N. S. Introdução á pesquisa em ciências sociais: a pesquisa qualitativa em educação. São Paulo: Atlas, 2012.

VALENTE, J. A. Análise dos diferentes tipos de softwares usados na Educação. In: VALENTE, J. A. (Org.). O computador na sociedade do conhecimento. Campinas, SP: Nied, 1999. Cap. 4, p. 81-85. 